\title{
Exploring perceptions of policymakers about main strategies to enhance fertility rate: A qualitative study in Iran
}

\author{
Ali Akbar Haghdoost ${ }^{1}$, Roya Safari-Faramani ${ }^{2}$, Mohammad Reza Baneshi ${ }^{3}$, Reza Dehnavieh ${ }^{4}$, Mahlegha \\ Dehghan $^{5}$
}

${ }^{1}$ Ph.D. of Epidemiology, Professor, HIV/STI Surveillance Research Center, and WHO Collaborating Center for HIV Surveillance, Institute for Futures Studies in Health, Kerman University of Medical Sciences, Kerman, Iran

${ }^{2}$ Ph.D. Candidate of Epidemiology, Modeling in Health Research Center, Institute for Futures Studies in Health, Kerman University of Medical Sciences, Kerman, Iran

${ }^{3}$ Ph.D. of Biostatistics, Associate Professor, Modeling in Health Research Center, Institute for Futures Studies in Health, Kerman University of Medical Sciences, Kerman, Iran

${ }^{4} \mathrm{Ph}$.D. of Health Service Management, Associate Professor, Social Determinant of Health Research Center, Institute for Futures Studies in Health, Kerman University of Medical Sciences, Kerman, Iran

${ }^{5}$ Ph.D. of Nursing, Assistant Professor, Nursing Research Center, Kerman University of Medical Sciences, Kerman, Iran

Type of article: Original

\begin{abstract}
Background: Total fertility rate in Iran has declined unprecedentedly over the past thirty years. However, debating on proper strategies to increase fertility is still a matter of discussion among experts.

Objective: To explain the main strategies to increase fertility from the viewpoints of the policy makers.

Methods: This is a qualitative study using content analysis. Purposeful sampling approach was used to gather data. The data were collected via semi-structured interviews. Eight experts participated in the study and the main criteria were executive experience related to public health, scientific publication in these areas and availability as well as their own interest. Content analysis was used to extract the codes.

Results: The main theme extracted was improving the infrastructures. Almost all participants agreed on interventions around removing marriage obstacles, improving working conditions for women, improving the quality of the educational system, training and consultation, research, and improving services to increase fertility rate.

Conclusions: The government should formulate long-term instead of short-term policies, and note that improving the economic conditions along with the promotion of social welfare, and enabling women in balancing work and family, are highly influential in childbearing decision-making, as they ensure a better future for the next generation. In addition, people should touch on the potential risk of future fertility reduction, so it is suggested to inform the public through free discussions.
\end{abstract}

Keywords: Iran, Population policy, Qualitative study, Fertility rate

\section{Introduction}

The decline in the overall fertility rate in some countries, which has commenced since the industrial revolution, continues to this date. Nowadays, 46 percent of the world's population lives in the low fertility area and this percent is growing. It is predicted that 120 countries will experience below-replacement fertility level by the mid $21^{\text {st }}$ century (1). Iran is no exception. Iran, which experienced a total fertility rate of around seven in the late 1970s, after an unprecedented decline, has been experiencing below-replacement fertility since the early 21 st century (2). Based

\section{Corresponding author:}

Roya Safari-Faramani, Modeling in Health Research Center, Institute for Futures Studies in Health, Kerman University of Medical Sciences, Kerman, Iran. Tel: +983433205092, Email: r.safari84@gmail.com

Received: January 01, 2017, Accepted: March 19, 2017, Published: October 2017

iThenticate screening: February 07, 2017, English editing: May 12, 2017, Quality control: September 12, 2017

This article has been reviewed / commented by Three experts

(C) 2017 The Authors. This is an open access article under the terms of the Creative Commons Attribution-NonCommercialNoDerivs License, which permits use and distribution in any medium, provided the original work is properly cited, the use is non-commercial and no modifications or adaptations are made. 
on the latest census in Iran (2011), total fertility rate was 1.8 children per woman and the growth rate was 1.3 percent. Twenty three percent of the population was under 15 years old,and around six percent were over 65 years old. In comparison with the previous census there is a 10.2 percent increase in the elderly population and around seven percent reduction in the young population $(2,3)$. Fertility reduction to the below-replacement level is one of the demographic challenges which can result in the reduction in population growth, population aging and finally population reduction. On the other hand, increasing the dependency ratio may lead to a problem in job marketing, and the social security systems may be overloaded (4).There is a lot of evidence on the causes of low fertility. It seems that fertility reduction is directly the result of the reduction in the number of children and postponement of the childbearing. Introduction of contraceptives, education especially in women, increasing women's job opportunities so increase in opportunity cost, value and ideational changes, economic aspiration, paying attention to the quality of the children, gender equity and economic uncertainty are among the causes for fertility reduction across different societies (4-7). Population growth rate has always been one of the major challenges in most countries (8). Developed countries, which have been dealing with the challenge of below-replacement fertility for a longer time, have formulated several policies to increase fertility rate (9). These policies include a wide variety of direct and ind irect policies, like improving welfare systems to empower the youth to bring up a family and accept childbearing, improving mothers' working conditions and child care services, and also financial incentives, as well as paternal leave $(6,9)$. Sometimes, improving the welfare systems, empowering the youth, and valuing maternal roles are targeted instead of increasing fertility directly (10). Luci-Greulichet al. emphasizes that policies like paternal leave, child care services, and financial incentives may have a positive effect on the couples' childbearing decision-making (11). Doepke et al. showed that the policies that discount the burden of child care on mothers, compared with policies like child subsidy, are twice as effective on increasing fertility (12). But one does not fit all. McDonald believes that every country should formulate its own policy package based on its specific situation and the main causes of fertility reduction (13). Iran has moved to pro-natalist policies since 2011. At first, the government limited family planning services as well as punitive laws in the fifth development plan. Also, sterilization surgeries were banned except for urgent cases and reversal surgeries became available for free. After a while, the Ministry of Health also aimed to promote fertility to the replacement level, thus replaced the former family planning program with the "reproductive health" program. In this program, one of the main goals is reducing the number of one-child couples. In addition, there are some rules to increase maternal leave, which most organizations implement currently. In addition, the Comprehensive Population and Family Excellence Plan bill has been proposed to the Iranian parliament which has still not been approved due to high financial burden. In recent years, formulation of policies for increasing the fertility rate has been one of the main concerns of the policymakers, in Iran. During this short time, there has been widespread criticism of the proposed policies (14-18). In fact, there is no consensus on what would be the most effective ways to increase fertility. This is partly due to the complexity of fertility issues. In the case when the dimensions of the issue are not well defined, asking the experts about the main strategies seems to be helpful. This study was aimed to explain the main strategies to increase fertility from the viewpoints of policy makers.

\section{Material and Methods \\ 2.1. Study setting and participants}

Regarding the subject, a qualitative approach was adopted for the present study to explore the point of views (1921). This is a qualitative study using content analysis. Purposeful sampling approach was used to gather tha data. The sampling started in July 2015 and ended in April 2016. Some of the experts were contacted by telephone in cooperation with the think tank of Kerman University of Medical Science. The letter for invitation to participate in the study including a clear description of the study, together with a proposed time and date for an appointment was sent to their office after the telephone call. In reply to the letter, they specified a time for interview. Also, additional experts were contacted by visiting their office based on their scientific publication. Interviews were held in their office. The sampling continued until data saturation was reached. The main criteria were executive experience and scientific qualification related to the health of the population and availability as well as their willingness. The experts specialized in the fields of demography, sociology, health, and epidemiology with executive experience related to the health of the population.

\subsection{Data Collection}

Semi-structured interviews were used to collect the data (20). The experts were asked for their opinion about the most effective strategies on fertility increase. One of the main questions, for instance, was about their experiences on the implemented policies in recent years. Exploratory questions were asked to clarify the issue. At the beginning of 
each interview, oral consent was obtained from the participants for recording their interviews. The average time of individual interviews was approximately one hour.

\subsection{Data analysis}

Two individuals independently transcribed the interviews. Interviews were transcribed verbatim by the first individual and checked by the second. The transcribed interviews were reviewed several times. Content analysis was used to extract the codes. Using the Graneheim, and Lundman approach for data analysis, the key theme and categories were extracted (22). The coding started by identifying meaning units. After shortening the text to condensed meaning units, codes were selected. All of the text was reviewed several times to extract codes. Codes were reviewed for similarity and categorizing in subcategories. After that categories were formed and then, themes were extracted.

\subsection{Trustworthiness}

Credibility, Dependability, Confirmability, and Transferability were provided to assess trustworthiness (23, 24).Credibility was provided by prolonged engagement in the subject as well as checking the results of the analysis by some of the participants (Member check). To provide confirmability, all stages of the study, from idea to reporting, were under the supervision of qualified teachers who had passed qualitative courses and also were experienced. To confirm transferability of the study, we tried to report the study clearly.

\subsection{Ethical consideration}

Ethical committee of Kerman University of Medical Sciences approved the research proposal. The ethical code is $\mathrm{k} / 93 / 583$. All participants provided verbal consent to participate and for publication of their de-identified information.

\section{Results}

Eight experts participated in the study. General characteristics of policymakers participating in the study are presented in Table 1. Because of ethical issues, only the main fields of specialization of the experts are reported. Almost all of the participants believed that in the process of policy formulation, health of all individuals within the population must be guaranteed, and they should be in a condition to be able to produce a high quality and creative generation. Most of them stated that childbearing is a personal decision and the choice is with the people but the government can play a facilitating role through providing a safe and suitable economic, social, and political situation. Therefore, formulating long-term indirect and evidence-based policies can be helpful. Also, they emphasized that implementing these policies needs the collective movement of all organizations, and that the Ministry of Health cannot shoulder these responsibilities by itself.

Table 1. Basic characteristics of the participants

\begin{tabular}{|l|l|l|}
\hline Participants' ID & Gender & Field of Specialization \\
\hline 1 & Male & Demography \\
\hline 2 & Female & Gynecology \\
\hline 3 & Female & Sociology \\
\hline 4 & Male & Biostatistics \\
\hline 5 & Male & Epidemiology \\
\hline 6 & Male & Neonatology \\
\hline 7 & Male & Demography \\
\hline 8 & Male & Demography \\
\hline
\end{tabular}

The most important suggestions to increase fertility as viewed by the policy makers and experts are presented in Table 2. The main extracted theme was improving infrastructures which consisted of 6 categories. Infrastructures needed for a better welfare system enables the public to make the right decision on childbearing and starting a family. Infrastructures means the basic condition for a better generation including requirements to start a family, rearing the children, and enabling working conditions for women to make a good decision on childbearing. The main extracted categories were removing obstacles to marriage (sub-categories: cultural issues, creating job opportunities, economic security, managing the housing market), improving women's working practices (subcategories: decreasing women's workload, job security and maternal leave), care services and training for the future generation (sub-categories: improving child care services and securing the future, improving educational and training services for the future generation), training and consulting (sub-categories: happy marriage education, 
reproductive health, family planning consultation, community involvement), research (sub-categories: evaluation of the interventions, causes of fertility reduction, grounds for divorce and planning preventive measures), improving services (sub-categories: developing the underprivileged areas, birth control services).

Table 2. Extracted theme, categories and subcategories of the main strategies for increasing fertility rate $\mathrm{n}$ Iran

\begin{tabular}{|c|c|c|}
\hline Theme & Category & Subcategory \\
\hline \multirow{16}{*}{$\begin{array}{l}\text { Improving } \\
\text { infrastructures }\end{array}$} & \multirow[t]{3}{*}{ Removing obstacle to marriage } & Cultural issues \\
\hline & & Creating job opportunities and economic security \\
\hline & & Managing the housing market \\
\hline & \multirow{2}{*}{$\begin{array}{l}\text { Improving women's working } \\
\text { practices }\end{array}$} & Decreasing women's workload \\
\hline & & Job security and maternal leave \\
\hline & \multirow[t]{2}{*}{$\begin{array}{l}\text { Care services and training for the } \\
\text { future generation }\end{array}$} & $\begin{array}{l}\text { Improving child care services and securing the } \\
\text { future }\end{array}$ \\
\hline & & $\begin{array}{l}\text { Improving educational and training services for } \\
\text { the future generation }\end{array}$ \\
\hline & \multirow[t]{4}{*}{ Training and consulting } & happy marriage education \\
\hline & & Reproductive health \\
\hline & & Family planning consultation \\
\hline & & Community involvement \\
\hline & \multirow[t]{3}{*}{ Research } & Evaluation of the interventions \\
\hline & & Causes of fertility reduction \\
\hline & & $\begin{array}{l}\text { Grounds for divorce and planning preventive } \\
\text { measures }\end{array}$ \\
\hline & \multirow[t]{2}{*}{ Improving services } & Developing the underprivileged areas \\
\hline & & Birth control services \\
\hline
\end{tabular}

\subsection{Removing obstacles to marriage}

Almost all of the participants believed that the most important and most effective approach towards sustainable fertility increase is removing marriage obstacles. They believed that one of the most important causes of fertility reduction is the increased marriage age and decreased tendency to marriage, most importantly caused by unemployment and economic uncertainty as well as problems in the housing market and heavy expenses of holding wedding ceremonies. This category consists of three subcategories of cultural issues, creating job opportunities and economic security, and managing the housing market. "...Once more I emphasize that facilitating marriage is very important, that is providing the proper requisites for marriage. One of the requirements is positive economic growth. High economic growth results in the reduction in the unemployment rate. In this situation, individuals will find jobs sooner and marry younger..." (P-1)

\subsubsection{Cultural issues}

According to the participants, one of the main problems to marriage is the heavy expenses of the wedding ceremony. They suggested that young people be encouraged to celebrate their marriage in mass wedding ceremonies and to avoid expensive parties and hold ceremonies at a low cost. "...We see all these students who get married in different universities so we can convince them to take part in mass wedding ceremonies without spending too much money..." (P-6)

\subsubsection{Creating job opportunities and economic security}

One of the most important issues and necessities is being employed. Participants believed that one of the main reasons for people to avoid getting married is unemployment and having no job security. They hoped that as the country booms economically, it will manage to resolve the unemployment problem. “...You know what is good?! When the country improves economically and we would have enough job opportunities, then we can hope people revise their marriage and childbearing decisions..." (P-4)

\subsubsection{Managing the housing market}

As viewed by the participants, one of the marriage obstacles was housing. They believed that it is the government who should empower the youth to have a house by removing real-estate from the capital market and also construct hierarchical buildings, so that each family can choose a house based on its composition and number of members. “...Imagine a $45 \mathrm{~m}^{2}$ apartment for a three-kid family! We can have a suitable policy to remove the realestate from the capital market, in this way, house prices will decrease ... construction of hierarchical buildings; 
imagine a young couple, they can live in a 20-25 $\mathrm{m}^{2}$ suite, then, after 2-5 years they will have $60-70 \mathrm{~m}^{2}$ house in which they can raise a child so if we build "Maskane Mehr" (Mehr Housing Initiative), it should be hierarchical..." $(\mathrm{P}-5)$

\subsection{Improving women's working practices}

One of the issues on which the participants emphasized, was paying special attention to the working women, who do not see the situation suitable for childbearing most of the time. They pointed out that regarding the growing social contribution of women, if we want to increase fertility, paying special attention to this group is necessary. Three subcategories were extracted, namely decreasing women's workload, guaranteeing maternal leave, and job security “...Look how many women in the reproductive age are employed... so it influences their pregnancy, why don't we think about them? I always say that 'what happens if women don't go to work tomorrow? The answer is, nothing works, no airports, no banks..." (P-2)

3.2.1. Decreasing the women's workload

One of the deciding factors to balance work and family for women is decreasing workload. The participants believed that there should be more emphasis on the fathers' role of financial support, and also the maternal roles must be highlighted so that there can be part-time jobs for women.“...One of the effective solutions is redefining women's jobs; for example, if we can decrease women's working hours from 8 hours a day to 4-5 hours a day, with lower salary. In comparison to men, we can highlight the fathers' role of financial support then; the fathers will shoulder the major part of the economic burden of the family..." (P-5)

\subsubsection{Job security and maternal leave}

Job security was one of the most important issues for participants. In addition, they were afraid of prolonging the maternal leave and stated that this can jeopardize women's job security. This problem was an issue mainly in the private sector. One of the participants said that: “...When we say that the maternal leave is 9 months instead of 6 months, this may make the employers look for a young single woman. I have seen some employers who don't employ married women and if they do, the employees have to commit not to have children. And the ones who are allowed maternal leave will never be allowed to come back..." (P-3). Also, most of the participants believed that, today, maternal leave is the main challenge for women. On one hand, maternal leave is not guaranteed in the private sector. On the other hand, different insurance organizations adopt different approaches. Maternal leave is considered 6 months for some of these organizations and 9 months for others. "...After two years we don't know, we still have doubts for allowing 6 or 9 months as maternal leave..." (P-2)

\subsection{Care services and training for the future generation}

Participants emphasized the quality of the population. They maintained that if we expect a creative and qualified generation, two items must be considered: child care services and the education system. The subcategories were educational and training services for the future generation and improving child care services.

\subsubsection{Improving child care services and securing the future}

Child care services including nurseries for looking after the young child was another important issue based on the participants' views. They believed that a children's care system should be provided to encourage society, especially women, for childbearing. This will have a considerably desirable effect on the mothers' mental welfare and child care. "...If she brings a child into the world, how can she care for her baby? If she leaves her job or takes unpaid leave, she cannot afford the expenses..." (P-2)

\subsubsection{Improving educational and training services}

In the viewpoint of the participants, one of the main concerns of the public was education and training. Some participants were worried about the quality of the educational system, and emphasized that having a qualified generation requires enhancing the quality of the educational system. “... School's atmosphere is neither suitable nor cultural or educational. So, it needs to be modified. Those in charge should think of a strategy and ask the experts for suggestions..." (P-5)

\subsection{Training and consulting}

The participants believed that the source of most problems in the family is lack of knowledge. Accurate and up to date information on healthy marriage, reproductive health, family planning, and population issues can help people make the right decision. On the other hand, negative perceptions about fertility and tendency towards single-child families should be rectified. This category consists of four subcategories, including long and happy marriage, reproductive health, family planning, and population issues.“...Hanging of posters of single-child families or disadvantages of pregnancy after 30 is wrong. These perceptions can be changed by elaborating that these programs belonged to the period when families had 7 children...” (P-1) 


\subsubsection{Happy marriage education}

Participants believed that young people, families, and society in general should be aware of the disadvantages of getting married late and of the preferable age of marriage. On the other hand, there should be suitable education and consultation to improve life skills in order to maintain a long and happy marriage. "...If he/she wants to get married tell him/her that it should be healthy, in a safe age range. Consult individuals about happy marriage as well as how to lead a long marriage..." (P-1)

\subsubsection{Reproductive health}

According to our participants, reproductive health education and the principals of sexual intercourse for all couples and even the youth in the marriage age should be considered, so that most of the sexually transmitted infections, and also infertility, can be prevented. Furthermore, increasing the couple's knowledge on the principles of sexual intercourse can decrease the amount of dissatisfaction and the related divorces, as a result. "...One of the reasons for getting a divorce is the couple's lack of knowledge about sexual issues, meaning that, they don't know the principles of sexual intercourse to satisfy their partners emotionally and sexually. We need to talk about it ... if we don't teach them, we will have to face all these cases of divorce..." (P-6)

\subsubsection{Family planning consultation}

The participants held that one of the issues which people should know about is family planning. Participants thought that couples should decide on the desired number of children and timing as well as the suitable birth interval, delaying childbearing, disadvantages of having a single child, and also the best method of contraception; and this should be tackled by the health workers, who must be responsible for providing appropriate educational programs. "...Give them the necessary information, if they have one child, there should be a short birth interval for the next child, if they don't want children anymore tell them about the best contraceptive method..." (P-2)

\subsubsection{Community involvement}

Being unaware of population issues not only makes the public opinion disturbed but it also makes them ignore its importance. Giving information on demography matters via mass media and free discussions can be effective, especially for the educated population. They mean that the key people must be aware of the necessity of fertility increase. In fact, they should touch the potential risk of the future fertility reduction and we should inform them through free discussion. "...Indeed, we haven't provided opportunities for free and in-depth discussion where people talk about their ideas freely on population issues..." (P-5)

\subsection{Research}

Policy makers who participated in this study regarded research as one of the suitable tools for making decisions in all aspects, including population policies. They believed that we should emphasize research on some important issues, including evaluation of the planned interventions, causes of fertility reduction, and grounds for divorce, to plan preventive measures and use the results for future planning. In this category, the extracted subcategories were evaluation of the intervention, causes of fertility reduction and grounds for divorce and planning of preventive measures.

\subsubsection{Evaluation of the interventions}

Our participants believed that there should be research to evaluate the effects of the intervention after formulating and implementing the policies, so that it can be evidence for future planning. "...There really should be research ... for example, if eliminating condoms, pills or sterilizations as a contraceptive method are recommended, we need to start an evaluation and find an answer to which one is more influential on fertility increase..." (P-1)

\subsubsection{Causes of fertility reduction}

The participants believed that when there is not enough knowledge about causes of fertility reduction we can't formulate comprehensive policies. If we find the obstacles, we can formulate more effective policies to overcome them. Investigating the delaying of marriage is also important. "... You know, we can't plan an effective intervention when we don't know the reasons as to why our sons or daughters don't get married..." (P-1)

\subsubsection{Grounds for divorce and planning preventive measures}

As stressed by the participants, divorce may result in a fear of marriage and act as a deterrent for getting married and childbearing. They believed that we must identify the grounds for divorce and plan appropriate preventive measures. “...So, we should identify the grounds for divorce ... prevent those we can prevent. They would turn into a bad example. When the divorce rate is high, the young people wouldn't dare to get married, they would say to themselves, 'most of our friends' marriages ended in divorce', so they avoid getting married at all..." (P-6) 


\subsection{Improving services}

Participants emphasized the importance of improving services and development of the underprivileged areas to reach a balanced growth across the country as well as a high-quality population. The subcategories in this category were developing underprivileged areas and family planning services.

\subsubsection{Developing underprivileged areas}

Regarding the differences in the total fertility rate across the Iranian provinces and districts, our participants believed that formulating policies based on the total fertility rate in each area is discriminatory and, thus, not effective. Developing the underprivileged areas in addition to the other policies is recommended. In this way, we can prevent rural to urban migration and ensure a balanced growth rate.“...So, you should develop the underprivileged areas first or educate them, this is correct, but smart policies are not recommended. It means that you should provide contraceptive methods for high fertility areas such as Sistan and Baluchestan. This is not good, it is discriminatory..." (P-1)

\subsubsection{Birth control services}

According to our participants, limitation of the family planning services at the onset of pro-natality policies in order to increase fertility rate is not compatible with the mission of this program, i.e. reproductive health. They believed that it can endanger the health of mother and child and result in increasing the number of unplanned pregnancies in disadvantaged groups who have limited access to contraceptives. One of the main suggestions was reintroducing the family planning services alongside all the other programs. They thought that we could guarantee the health and quality of the population and also help couples realize their desired family size via appropriate consulting and family planning services. "...It should be a free decision. Everyone can have any number of children. The contraceptives should be changed by the time, by the situation, but the family planning is essential for people..." $(\mathrm{P}-1)$

\section{Discussion}

Based on the results of this study, it seems that implementing policies for increasing fertility in Iran, needs improvement of the infrastructures in order to generate a high-quality population. These infrastructures should be completed in order to encourage young people to marry, empower women in balancing work and family, improve child care, educational and training services, and education, and also, raise public awareness on issues related to health and population. In addition, the planned interventions need to be evaluated. In Iran, childbearing outside marriage and family, like many countries in the Eastern and South-Eastern Asia is not socially acceptable. As a result, one of the most basic principles to increase fertility is increasing the marriage rate and to prevent the increase of age at marriage. Age at marriage for girls and boys has increased 3.6 and 3.1 years, respectively, since the mid1980s (25). However, this increase in age at marriage is due to the increased access to education, but more importantly, to the economic stagnation of the first decade of the twenty-first century and failure to achieve the planned economic growth followed by the increasing unemployment rate. Currently, around 12 percent of the population older than 10 years is unemployed (25). Most of the countries like Iran, where childbearing outside marriage is not acceptable, have the same problem. In Japan, the main reason for fertility reduction after 1970 is due to a reduction in the marriage rate, which is mainly because of increased job opportunities for women and a decrease in such opportunities for men (26). In Italy, marriage is popular, and childbearing outside marriage is not common. In this country, one of the reasons for delaying marriage is difficulty in getting married owing to the labor market and lack of family support policies (27). The Netherlands is a successful example in this regard, where the strengthening of the welfare system and empowerment of the youth for starting a family and childbearing has enabled them to hold the total fertility rate over 1.7 (10). Paying attention to the economic wellbeing, because of its key role in marriage and childbearing, can be considerably useful. The economic climate is an influential factor on fertility with different pathways. In Europe, the fertility rate has decreased during the economic recession (28). Also, in Asian countries, economic growth had a positive effect on fertility rate (29). In Australia, evidence shows that education, income, and occupation were more influential than financial incentives or child care subsidy during 2001 to 2008. A "Window of Opportunity" has been opened in Iran in the recent decade (30). So that it seems that it is a good opportunity for Iran to boost the economy (31). Regarding Iranian culture and the importance of economic climate in childbearing decision making, economic growth may play a key role. Women's social contribution has been highlighted by expanding their access to education, but it didn't ensure job opportunities in Iran. Nowadays, we cannot ignore the social contribution of women. The inadequate and low quality of child care services for these women is one of the main concerns, as expressed by the participated experts. In recent years, these services have not been provided for government employees; a subsidy was considered instead. This proves to be the problem for most women. Evidence on family-friendly policies and their impact on the couples' childbearing decision-making are abundant. In Norway, increasing the quality of child care services had a considerable effect on fertility increase (32). Luci-Greulich, et al. showed that paid leave, child care services, and financial transfer have a positive effect on 
fertility (11). There is evidence that policies which reduce the burden of childcare on mothers have a greater effect on the childbearing decision (12). So, if we want to increase the number of children, facilitating child care will be a necessity. The declining trend of fertility in Iran had started before implementing the family planning initiative in 1989. It seems that this collective decision of population to decrease birth rate was more influenced by the socioeconomic conditions than the availability of family planning services (33). Developing health care services, rural development, economic problems, unemployment, paying attention to the quality of children, increased child raising expenses, decreased child demand, increased child survival rate, women's autonomy, and access to education, were all influential factors on fertility (34-37). In this situation, access to contraceptives helped couples to realize their desired family size and also improved reproductive health (38). Regarding the protective role of family planning on maternal mortality and child survival, limitation of this program not only fails to ensure fertility increase, but it may even endanger mother and child health and moreover, increase the number of unplanned pregnancies and, as a result, abortions. Recently, the Iranian Ministry of Health has replaced a new program entitled "Healthy Fertility" instead of Family Planning. As health is a right for all, and considering the collective decision of the population to decrease birth rate, the environment needs to be ready for couples to decide on the number of children and their desired timing. Therefore, as access to contraceptives is ensured, increasing public awareness about the disadvantages of delayed childbearing, infertility, and having a single child, and also the advantages and disadvantages of each one of the contraceptive methods is recommended. Only in this case is there a hope that people can make the right decisions. Most of the measures that governments have taken to encourage childbearing can affect the decisions of individuals, and may even determine the number or timing. What is important is the timely evaluation of these measures in order to ensure their effectiveness. Several studies have been conducted on the impact of these policies on fertility, and have shown different results. There is a review study conducted in European countries showing a positive effect of these policies $(5,9,11,32)$. As Iran is not very experienced in pronatalist policies, it seems that the evaluation of the related interventions is one of the most important issues. For this purpose, information systems such as Civil Registration and Statistical Center of Iran should set a minimum number of variables necessary for the proper evaluation of interventions. To our knowledge, this is the first study aimed at exploring the main strategies of fertility increase as viewed by the policy makers and experts. For this new situation, the findings of the present study may be a helpful evidence to formulate appropriate policies. The qualitative approach would be appropriate when different aspects of the problem are not defined and clear.

\section{Conclusions}

Based on the results of the present study, the best suggestions are empowering the youth to start a family via increasing job opportunities, job security and managing the housing market, empower women in balancing work and family, improve child care, educational and training services, and educate youths on related topics on family planning, marriage, reproductive health. In addition, people should touch the potential risk of future fertility reduction and we should inform them. This is a very useful evidence for effective policy making. Belowreplacement fertility is a new situation in Iran. In this situation, the youth and the families are the key populations. So, investigating the youth is vital. More research on effective policies and the effect on the implemented policies is recommended.

\section{Acknowledgments:}

This study is a part of Ph.D. thesis. The authors would like to thank the think tank of Kerman University of Medical Sciences and the participating experts for their significant contribution in conducting this study.

\section{Conflict of Interest:}

There is no conflict of interest to be declared.

Authors' contributions:

All authors contributed to this project and article equally. All authors read and approved the final manuscript.

\section{References:}

1) United Nations, Department of Economic and Social Affairs, Population Division (2015). World Population Prospects: The 2015 Revision, Key Findings and Advance Tables. Working Paper No. ESA/P/WP.241.

2) McDonald P, Hosseini Chavoshi M, Abbasi Shavazi MJ, Rashidian A. An assessment of recent Iranian fertility trends using parity progression ratios. Demographic Research. 2015; 32: 1581-602. doi: 10.4054/DemRes.2015.32.58. 
3) Findings of 2011 national population and household census. Statistical Centre of Iran; 2011.

4) Schleutker E. Determinants of Childbearing: A Review of the Literature. Zeitschrift für Soziologie. 2014; 43(3): 192-211.

5) McDonald P. Low fertility and policy. Ageing Horizons. 2007; 7: 22-7.

6) Balbo N, Billari FC, Mills M. Fertility in Advanced Societies: A Review of Research: La fécondité dans les sociétés avancées: un examen des recherches. Eur J Popul. 2013; 29(1): 1-38. doi: 10.1007/s10680-0129277-y. PMID: 23440941, PMCID: PMC3576563.

7) Mills M, Rindfuss RR, McDonald P, Te Velde E. Why do people postpone parenthood? Reasons and social policy incentives. Hum Reprod Update. 2011; 17(6): 848-60. doi: 10.1093/humupd/dmr026. PMID: 21652599 , PMCID: PMC3529638.

8) Ezeh AC, Bongaarts J, Mberu B. Global population trends and policy options. The Lancet. 2012; 380(9837): 142-8. doi: 10.1016/S0140-6736(12)60696-5.

9) Frejka T, Gietel-Basten S. Fertility and Family Policies in Central and Eastern Europe after 1990. Comparative Population Studies. 2016; 41(1): 3-56. doi: 10.12765/CPoS-2016-03en.

10) Mills MC. The Dutch Fertility Paradox: How the Netherlands Has Managed to Sustain Near-Replacement Fertility. Springer . 2015; 161-88. doi: 10.1007/978-3-319-21482-5_9.

11) Luci Greulich A, Thévenon O. The Impact of Family Policies on Fertility Trends in Developed Countries. European Journal of Population / Revue européenne de Démographie. 2013; 29(4): 387-416. doi: 10.1007/s10680-013-9295-4.

12) Doepke M, Kindermann F. Bargaining over Babies: Theory, Evidence, and Policy Implications. 2016. doi: 10.3386/w22072.

13) McDonald P. Sustaining fertility through public policy: The range of options. Population. 2002; 57(3): $417-$ 46. doi: 10.3917/popu.203.0423.

14) Aloosh M, Aloosh A. Iran: the health cost of a political order. Lancet. 2014; 384(9958): 1926-7. doi: 10.1016/S0140-6736(14)62277-7. PMID: 25435449.

15) Aloosh M, Saghai Y. Birth control policies in Iran: a public health and ethics perspective. J Epidemiol Community Health. 2016; 70(6): 529-33. doi: 10.1136/jech-2015-205572. PMID: 26759127.

16) Erfani A. Curbing family planning in Iran: an appraisal of Bill 446. J Fam Plann Reprod Health Care. 2015; 41(4): 317-8. doi: 10.1136/jfprhc-2015-101254. PMID: 26399596.

17) Karamouzian M, Sharifi H, Haghdoost AA. Iran's shift in family planning policies: concerns and challenges. Int J Health Policy Manag. 2014; 3(5): 231-3. doi: 10.15171/ijhpm.2014.81. PMID: 25337596, PMCID: PMC4204741.

18) Bagheri Lankarani K. Changing Population Policy in Iran. Shiraz E-Med J. 2015; 16(2): e27537. doi: $10.17795 / \operatorname{semj} 27537$.

19) Malterud K. Qualitative research: standards, challenges, and guidelines. lancet. 2001; 358(9280): 483-8. doi: 10.1016/S0140-6736(01)05627-6. PMID: 11513933.

20) Pope C, Mays N. Qualitative research in health care: Blackwell Publishing Ltd; 2006. doi: 10.1002/9780470750841.

21) Speziale HS, Streubert HJ, Carpenter DR. Qualitative research in nursing: Advancing the humanistic imperative: Lippincott Williams \& Wilkins; 2002.

22) Graneheim UH, Lundman B. Qualitative content analysis in nursing research: concepts, procedures and measures to achieve trustworthiness. Nurse Educ Today. 2004; 24(2): 105-12. doi: 10.1016/j.nedt.2003.10.001. PMID: 14769454.

23) Guba EG. Criteria for assessing the trustworthiness of naturalistic inquiries. Educational Technology Research and Development. 1981; 29(2): 75-91. doi: 10.1007/BF02766777.

24) Lincoln YS. Emerging criteria for quality in qualitative and interpretive research. Qualitative inquiry. 1995; 1(3): 275-89.

25) Statistical Centre of Iran [cited 06/02/2017].

26) Tsuya NO. Below-Replacement Fertility in Japan: Patterns, Factors, and Policy Implications. Low and Lower Fertility: Springer; 2015; 87-106.

27) Saraceno C. The Italian family from the 1960s to the present. Modern Italy. 2004; 9(1): 47-57. doi: 10.1080/13532940410001677494.

28) Goldstein J, Kreyenfeld M, Jasilioniene A, Örsal DDK. Fertility reactions to the" Great Recession" in Europe: Recent evidence from order-specific data. Demographic Research. 2013; 29: 85-104. doi: 10.4054/DemRes.2013.29.4. 
29) Spoorenberg T. Explaining recent fertility increase in Central Asia. Asian Population Studies. 2015; 11(2): 115-33. doi: 10.1080/17441730.2015.1027275.

30) Parr N, Guest R. The contribution of increases in family benefits to Australia's early 21 st-century fertility increase: An empirical analysis. Demographic Research. 2011; 25(6): 215-44. doi: 10.4054/DemRes.2011.25.6.

31) Hosseini H. Demographic Transition, Window of Opportunity, and Population Bonus: Toward a New Population Policy in Iran. Paper Accepted for Presentation at the European Population Conference, Stockholm, Sweden; 2012.

32) Fent T, Diaz BA, Prskawetz A. Family policies in the context of low fertility and social structure. Demographic Research. 2013; 29(37): 963-98. doi: 10.4054/DemRes.2013.29.37.

33) Abbasi Shavazi MJ, McDonald P, Hosseini Chavoshi M. The Fertility Transition in Iran: Revolution and Reproduction. 1 ed: Springer Netherlands; 2009; 17-42.

34) Abbasi MJ, Mehryar A, Jones G, McDonald P. Revolution, war and modernization: Population policy and fertility change in Iran. Journal of Population Research. 2002; 19(1): 25-46. doi: 10.1007/BF03031967.

35) Chavoshi MH, Abbasi Shavazi MJ, McDonald P. Women's autonomy and reproductive behavior in Iran. The Fertility Transition in Iran: Revolution and Reproduction: Springer Netherlands; 2004; 163-77.

36) Aghajanian A. A new direction in population policy and family planning in the Islamic Republic of Iran. Asia-Pacific population journal/United Nations. 1995; 10(1): 3-20.

37) Salehi Isfahani D, Abbasi Shavazi MJ, Hosseini Chavoshi M. Family planning and fertility decline in rural Iran: The impact of rural health clinics. Health economics. 2010; 19(S1): 159-80. doi: 10.1002/hec.1613.

38) Cleland J, Conde-Agudelo A, Peterson H, Ross J, Tsui A. Contraception and health. Lancet. 2012; 380(9837): 149-56. doi: 10.1016/S0140-6736(12)60609-6. PMID: 22784533. 